\title{
From Teratogens to Potential Therapeutics: Natural Inhibitors of the Hedgehog Signaling Network Come of Age
}

Authors

Affiliation
Amalya Hovhannisyan, Madlen Matz, Rolf Gebhardt

Institute of Biochemistry, Medical Faculty, University of Leipzig, Leipzig, Germany
Key words

- Veratrum californicum (Durand)

- Liliaceae

- cyclopamine

- Hedgehog signaling

- homeostasis

- tumor

- psoriasis received March 19, 2009 revised June 14, 2009 accepted June 17, 2009

\section{Bibliography}

DOI 10.1055/s-0029-1185979

Published online July 28, 2009

Planta Med 2009; 75 :

1371-1380 @ Georg Thieme Verlag KG Stuttgart · New York · ISSN 0032-0943

\section{Correspondence}

Prof. Dr. Rolf Gebhardt

Institut für Biochemie

University of Leipzig

Johannesallee 30

04103 Leipzig

Germany

Phone: +493419722100

Fax: + 493419722109

rgebhardt@

medizin.uni-leipzig.de

\section{Abstract}

$\nabla$

Steroidal alkaloids from Veratrum californicum (Durand) are known to exert teratogenic effects (e.g., cyclopia, holoprosencephaly) by blocking the Hedgehog (Hh) signaling pathway, which plays a considerable role in embryonic development and organogenesis. Most surprisingly, recent studies demonstrate that this complex signaling network is active even in the healthy adult organism, where it seems to control important aspects of basic metabolism and interorgan homeostasis. Abnormal activation of Hh signaling, however, can lead to the development of different tumors, psoriasis, and other diseases. This review

provides an overview of how the principle teratogenic and hazardous constituent of Veratrum californicum, cyclopamine, interferes with Hh signaling and can potentially serve as a beneficial therapeutic for different tumors and psoriasis.

$\begin{array}{ll}\text { Abbreviations } \\ \nabla \\ \text { Hh: } & \text { Hedgehog } \\ \text { Shh: } & \text { Sonic Hedgehog } \\ \text { Ptch1: } & \text { Patched } 1 \\ \text { Smo: } & \text { Smoothened } \\ \text { Hhip1: } & \text { Hedgehog-interacting protein } 1 \\ \text { EMT: } & \text { epithelial-mesenchymal transition }\end{array}$

Veratrum californicum (Durand) and Teratogenic Effects Leading to Holoprosencephaly and Cyclopia

$\nabla$

In 1963, Binns et al. [1] described the development of congenital cyclopean-type malformations in lambs following maternal ingestion of the range plant Veratrum californicum (Durand). While cattle, sheep, rat, and rabbit embryos under such conditions develop mainly cyclopia, chicken embryos preferentially develop holoprosencephaly [1-4]. Holoprosencephaly is a developmental field defect of impaired midline cleavage of the embryonic forebrain (for reviews, see [5] and [6]). However, there is a wide phenotypic spectrum depending upon the specific cause of this malformation. In its most extreme form, it is associated with cyclopia, which is characterized by one eye being located centrally over the root of the nose ( Fig. 1). In sheep such effects occur when pregnant ewes are exposed on day 14 of gestation. The most frequent defects caused by exposure at later periods of gestation, around day 30 , are limb deformities, palate defects, and severe tracheal stenosis [7]. All these defects in the whole spectrum of their expression have counterparts in humans; however, their causes are unknown, in contrast to the situation in exposed animals, where constituents of plants of the genus Veratrum were found to be responsible.

\section{Plants of the Genus Veratrum and Their Teratogenic Constituents $\nabla$}

Plants of the genus Veratrum (Liliaceae) are found all over the world, with many different species in Eurasia and America. Typical habitats are (sub)alpine with humid, acidic soils. Veratrum californicum is found in North America in restrictive habitats such as high, moist meadows. It propagates by rhizome and grows in dense, sharply defined stands. Analysis of extracts of Veratrum californicum by Keeler and Binns led to the identification of steroidal alkaloids as the cause of holoprosencephaly [8]. Among the isolated compounds were cyclopamine (11-deoxojervine), jervine, and cycloposine (3-glucosyl-11-deoxojervine) (๑ Fig. 2), which are closely related C-nor-D-homo-steroids with a fused furanopiperidine-at- 


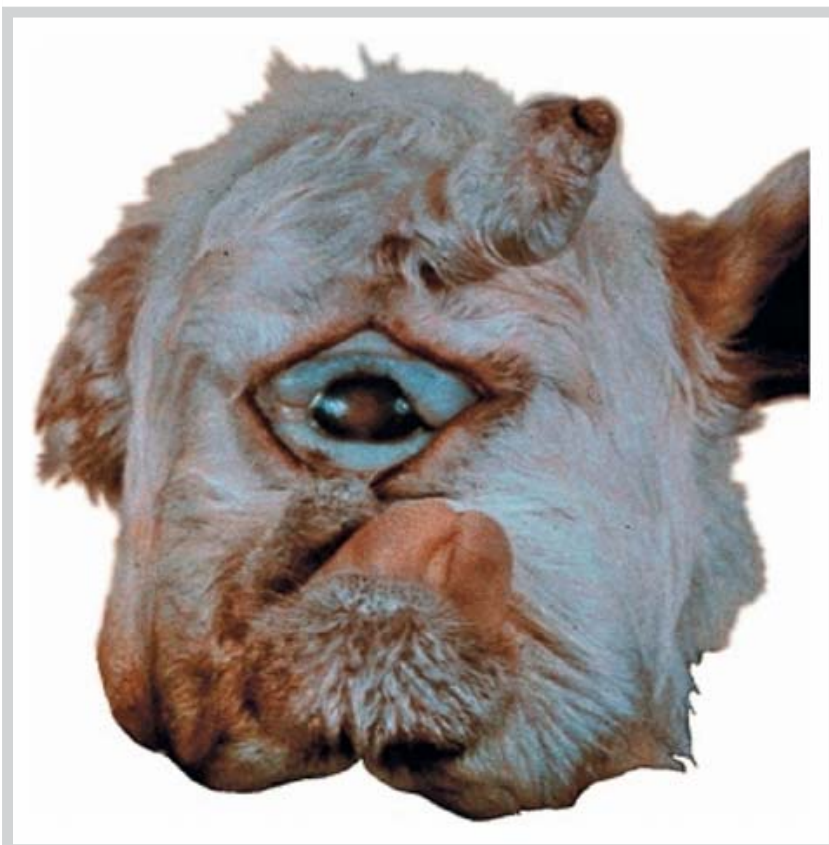

Fig. 1 Cyclopean-type birth defect in a lamb induced by maternal consumption of Veratrum californicum. Reproduced from ref. [74].

tached spiro at carbon 17 of the steroid [9]. Cyclopamine is the principle teratogen because of its high concentration in Veratrum californicum, while jervine appears to be more abundant in Veratrum viride roots. Related steroidal alkaloids such as veratramine, veratrosine, and germine are found in the roots and rhizomes of different Veratrum species $[10,11]$. Those lacking the furan ring (๑ Fig. 2) do not induce cyclopia [9] but may lead to other congenital birth defects and different types of toxicities [11,12]. Because of its potential medicinal use, in vitro techniques for propagating Veratrum californicum have been developed [13].

\section{Sonic Hedgehog Signaling as the Target of Cyclopamine}

In 1996, mutations in the human Sonic Hedgehog (Shh) gene were found to cause holoprosencephaly [14]. Likewise, mice lacking the homolog gene developed cyclopia and other defective axial patterning [15]. Following these observations, cyclopamine and jervine were found to exert their teratogenic action by blocking the Hedgehog (Hh) signaling pathway [16]. Because Hh signaling is one of the complex signaling cascades regulating embryonic development $[17,18]$, it is not surprising that cyclopamine at very different times of embryogenesis inhibits multiple morphological processes in many tissues. While developmental issues of Hh signaling and its inhibition by cyclopamine have been the subject of many reviews [19-21], its role in adults has not yet received as much attention. In this review, we will focus mainly on phenomena exerted by Hh signaling in healthy adults - different types of cancer, cancer cells, and psoriasis - and will highlight the effects caused by cyclopamine.

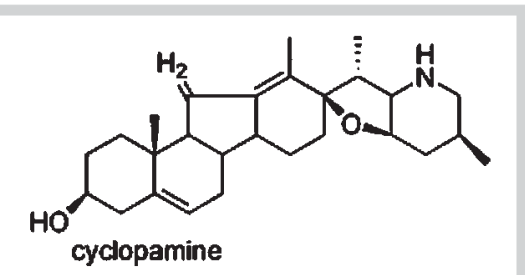

Fig. 2 Molecular structures of some Veratrum alkaloids.<smiles>CC1=C2C(=O)[C@H]3C(CC=C4C[C@@H](O)CC[C@@]43C)C2CC[C@]12O[C@H]1C[C@H](C)CNC1[C@H]2C</smiles><smiles>Cc1c([C@@H](C)[C@H]2NC[C@@H](C)C[C@H]2O)ccc2c1CC1C2CC=C2C[C@H](OCl)CC[C@@]21C</smiles>

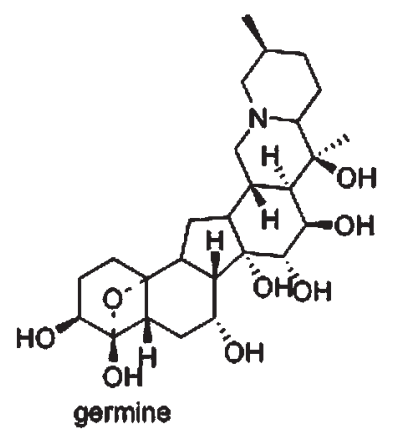

\section{Basic Features of the Hedgehog Signaling Pathway and Molecular Actions of Cyclopamine \\ $\nabla$}

Despite its complexity and many unsolved aspects, a basic scheme of the canonical Hh signaling pathway can be delineated that seems highly conserved throughout evolution ( $\odot$ Fig. 3) (for reviews, see [17] and [18]). In mammals, three Hh genes have been identified: - Sonic, Indian, and Desert. One key feature of the Hh proteins is their modification by lipids (cholesterol and palmitic acid), which considerably influences their solubility and range of action [22-25]. However, traffic over larger distances mediated by lipoproteins is also possible [26]. At the target cell, $\mathrm{Hh}$ molecules interact with the 12-pass membrane $\mathrm{Hh}$ receptor Patched (Ptch). In the absence of Hh ( Fig. 3A), Ptch seems to act as a transporter, exporting vitamin D3 or a precursor [27] that blocks the seven-pass $G$ protein-coupled receptor Smoothened (Smo) [28]. Hh binding inhibits the catalytic function of Ptch, leading to activation of Smo by oxysterols ( Fig. 3B). Active Smo subsequently propagates the signal elicited by Hh to downstream effectors (i.e., to members of the Gli/ Ci family of zinc-finger transcription factors). The intracellular signal propagation involves a plethora of proteins [e.g., Costal2 (Cos2), Fused (Fu), and Suppressor of Fused (SuFu)] arranged in large protein complexes, the composition and function of which may vary in different species and is poorly defined so far. The Gli factors of vertebrates (Gli1, Gli2, and Gli3) serve different func- 


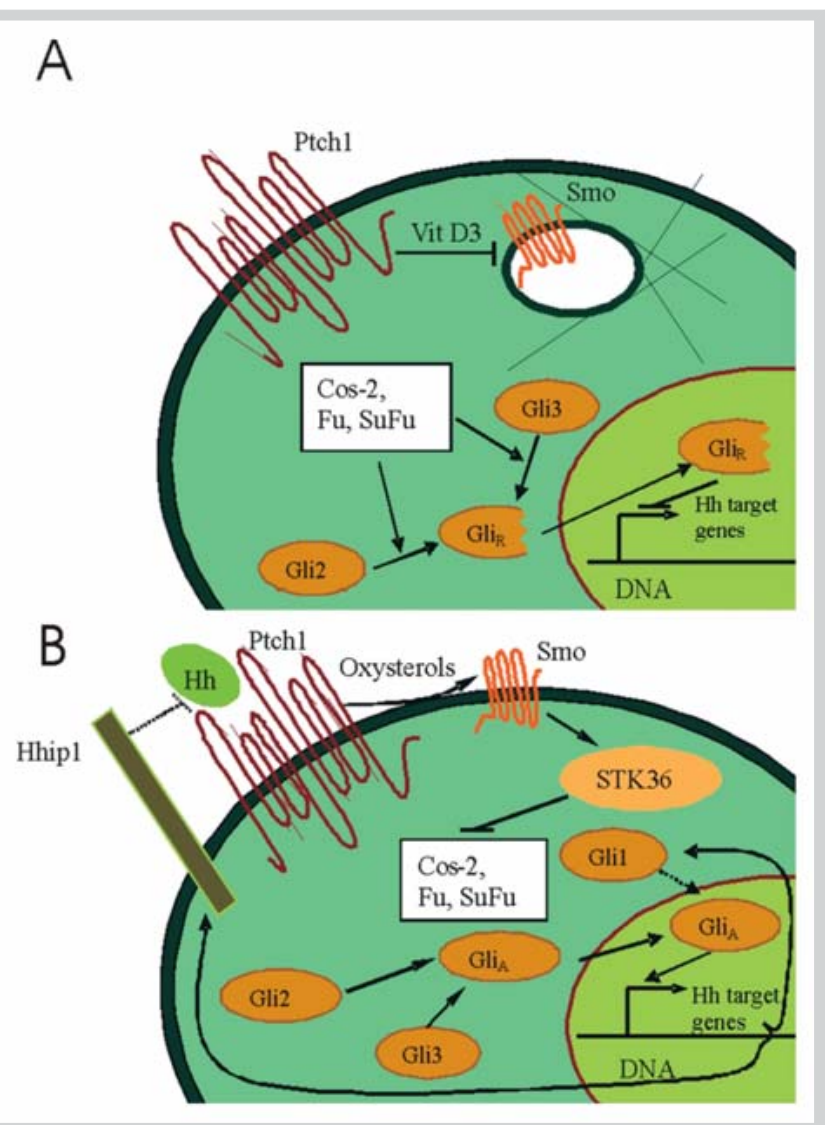

Fig. 3 Schematic illustration of the mammalian Hedgehog signaling pathway in the absence or presence of Hedgehog ligands. A In the absence of available Hh, Ptch1 inhibits Smo by a vitamin D3-dependent mechanism. At this time, $\mathrm{Gli2}$ and $\mathrm{Gli3}$, in the complex with Cos-2, Fu, and SuFu, undergo proteolytic processing into their truncated repressor forms, which can inhibit transcription of $\mathrm{Hh}$ target genes. B The binding of $\mathrm{Hh}$ to Ptch relieves its repression of Smo and allows it to be activated by oxysterols. Activated Smo inhibits the Cos-2, Fu, and SuFu complex through STK36, allowing accumulation of the full-length activator forms of Gli2 and Gli3. Activator forms of Gli then initiate transcription of $\mathrm{Hh}$ target genes, including Gli1 and Hhip1. Gli1 is a constitutive transcriptional activator of the pathway, whereas Hhip1 is the negative regulator of Hh signaling. tions. While Gli2 and Gli3 posses both repressor and activator domains flanking a DNA-binding domain, Gli1 lacks the repressor domain and functions mainly as a co-activator of Gli2 $[20,29]$. In cells not exposed to Hh signals ( $\bullet$ Fig. 3A), Gli2 and Gli3 undergo proteolytic cleavage by the proteasome [30] to yield truncated forms that act as repressors of gene transcription after nuclear translocation. Once Hh signaling is activated ( $\bullet$ Fig. 3B), cleavage and/or degradation is blocked, resulting in the nuclear import of full-length Gli2 and Gli3 proteins that now act as activators of target gene expression. Among the target genes of $\mathrm{Gli} 2$ are $\mathrm{Bcl}-2$, cMyc, Gli1, Ptch1, and Hhip1 (Hedgehog-interacting protein 1, a feedback inhibitor of Hh ligands) and many genes involved in proliferation ( $\bullet$ Fig. 3). Interestingly, Gli transcription factors not only are regulated by Hh signaling but also may respond to other signaling pathways [31].

Cyclopamine was found to inhibit Hedgehog signaling by directly binding to Smo [32]. This, in turn, blocks the activating effects of oxysterols on Smo and interrupts all downstream signaling.
There is, however, no direct competition of cyclopamine and oxysterols for the same binding site on Smo [20]. Instead, cyclopamine seems to act comparably to vitamin D3 or its precursor [27] and may share the same binding site. Indeed, in one study, cyclopamine replaced vitamin D3 from recombinant Smo protein with an apparent dissociation constant of $2 \mathrm{nM}$ [27]. It is assumed that other steroidal alkaloids such as jervine behave accordingly. In in vitro assays on taste papilla development, cyclopamine and jervine revealed a similar potency for inhibiting Hh signaling [33].

\section{Hedgehog Signaling in the Physiology of the Adult Body \\ $\nabla$}

\section{The importance of Hh signaling in stem cells}

Various studies have now demonstrated the function of Hh signaling in the control of cell proliferation, especially for stem cells and stem-like progenitors in adults [34-36]. Hh signaling has been found to play a role in regulating the self-renewal of normal stem cells in the skin, nervous system, breast, and hematopoietic system. Hh activation also increases the proliferation of mammary progenitor cells [37]. It has been shown that Hh signaling is also required in the stem cell niches of the gonads and bone marrow [38] and is strongly implicated in maintaining stem cell niches in the stomach [39].

\section{Central nervous system}

Endogenous Shh plays a role in the generation of serotonergic, GABAergic, and dopaminergic cells from mesencephalic precursors and promotes their survival as a trophic factor [40]. Hh signaling also plays a neuroprotective role by increasing the expression of brain-derived neurotrophic factor, whereas cyclopamine reduces it [41].

In the postnatal cerebellum, Shh expressed by Purkinje cells may act on its target receptor complex localized in the external germinative layer to activate Gli1 and stimulate proliferation of rat cerebellar granule cell neuroblasts. In the adult brain, Ptch and Smo transcripts are co-localized in a few areas such as the hippocampal granule cells. However, Ptch transcripts are also observed without any detectable Smo expression, such as in the superior colliculus [42].

\section{Gastrointestinal tract}

It was shown that Hh signaling is an important regulator in homeostatic processes of the adult stomach, colon, and pancreas. Throughout adult life, Hh signaling is strongly implicated in the differentiation of gastric and intestinal epithelium and maintains their specificity [43]. Cyclopamine treatment for 14 days markedly disturbs enterocyte maturation. In the island of murine pancreas, the Hh signaling pathway plays an important role in the regulation of insulin production. The administration of cyclopamine decreases insulin I promoter activity, insulin secretion and the insulin content of pancreatic cells [39].

Various contributions of the Hh pathway during adult liver injury have recently been reviewed [44]. Depending on the cause and the specific type of (chronic) injury, regenerative processes are accompanied by upregulation of Hh signaling in bile duct epithelial cells, hepatic stellate cells, and/or progenitor cells. Whether cyclopamine may slow down regeneration is not known. 


\section{Testis}

Hh signaling positively influences cell proliferation in the adult testis, and both Sertoli and germ cells are targets of Hh activity. Treatment with cyclopamine causes defects in spermatogenesis and reduces fertility [45].

\section{Immune system}

Hh proteins function in the maintenance of intrathymic CD34 precursor cell populations. The survival and function of human thymic dendritic cells (which play an important role by presenting self-antigens and inducing apoptotic death of potentially autoreactive developing T cells) are also dependent on autocrine $\mathrm{Hh}$ signaling. Cyclopamine decreases the viability and function of thymic dendritic cells [46]. It is certain that the Hh pathway regulates immune system functioning; however, the critical question as to whether Hh signaling is protective or pathogenic remains unanswered. In some immunopathologic disorders, the Shh pathway functions as a possible repair mechanism, but it could also have a damaging effect [39].

\section{Cardiovascular system}

Hh signaling is required for adult cardiac homeostasis to maintain proangiogenic gene expression and promote survival of the coronary microvasculature. The temporal and tissue-specific deletion of Smo leads to a reduction in proangiogenic gene expression and dropout of coronary blood vessels, resulting in tissue hypoxia, cardiomyocyte apoptosis, ventricular failure, and lethality [47-49]. However, Bijlsma et al. [50] have supposed that Hh expression exerts a dualistic action during cardiac ischemia, in that high exogenous levels are able to foster tissue repair while endogenous Hh seems to be deleterious, causing left ventricular dilatation and reduced cardiac output. They showed that cardiac muscle vascularization is similar in cyclopamine-treated and control-treated animals but that apoptosis is increased and fibrosis is reduced in the cyclopamine-treated animals.

\section{Bones}

Recent results provide evidence that Hh signaling plays a crucial role in postnatal bone homeostasis and point to Hh signaling as a potential molecular target for the treatment of osteoporosis. Systemic administration of the Hh signaling inhibitor cyclopamine decreased bone mass in adult mice [51].

\section{Adipogenesis, fat mass, and body weight}

There is plenty of evidence that Hh signaling plays an important role in fat formation and adipogenesis during postnatal development [52]. Experiments on cultured cells suggest that Hh signaling shows anti-adipogenic properties [53]. Thus, differentiation of preadipocytes is inhibited by Shh [54], and maturation of human adipose stem cells is inhibited by purmorphamine, a Hh signaling agonist [55]. While it is established that activation of $\mathrm{Hh}$ signaling results in inhibition of adipogenic differentiation and that downstream components of Hh signaling are downregulated during adipogenesis [54,56], the question of whether inhibition of Hh signaling is necessary and sufficient to induce adipocyte differentiation is still a matter of debate $[53,54]$. In a number of cell systems, inhibition of Hh signaling, e.g., by cyclopamine, was found to be necessary but not sufficient for this process [55-57]. In contrast to these findings in vitro, most experiments leading to stimulation of Hh signaling in vivo tend to enhance both fat mass and body weight. In adult mice, injection with Shh-IgG fusion protein caused a significant increase in fat mass and body weight without affecting food consumption [58]. In line with these results, mutations in Ptch that activate Hh signaling were associated with increased body weight in mice in utero [59] and in humans, as observed in Gorlin's syndrome [60]. Conversely, inhibition of Hh signaling using neutralizing antibodies protected mice against diet-induced weight gain [61]. In this instance, partial impairment of intestinal absorption of fat, particularly of triglycerides, might be involved [61]. Administration of the same antibodies in utero or immediately after birth decreased plasma cholesterol levels and lipid accumulation in enterocytes and induced fatty stools [62]. Similar inhibition of Hh signaling in adult $A p o E^{-1-}$ mice, which develop arteriosclerotic lesions when fed normal chow or Western-type diets, increased total plaque area and stimulated foam cell formation, while plasma cholesterol levels were decreased [63]. No weight gain was observed, most probably because of inhibition of intestinal fat absorption as described for normal mice [61].

On the contrary, however, adult mice bearing a specifically truncated Ptch1, causing them to suffer from spontaneous mesenchymal dysplasia, were found to show reduced white fat mass [64]. Together, these results show that Hh signaling has a complex impact on many aspects of lipid metabolism and adipogenesis in adult animals, but the influence may vary with the specific type of activation or inhibition of the signaling pathway and may depend on whether Hh signaling is affected globally or only in specific organs and cells. So far, no long-term studies using cyclopamine have been performed. However, on the basis of the data reviewed above, one may expect that chronic administration of cyclopamine will have considerable impact on lipid metabolism throughout the body.

\section{Role of the Hh Pathway in Tumorigenesis $\nabla$}

An increasing body of evidence documents the implication of $\mathrm{Hh}$ pathway hyperactivation in cancers such as skin, brain, gastrointestinal tract, lung, prostate, and breast cancers and oral squamous cell carcinomas [65-69]. The list of tumors reported to be Hh dependent is steadily growing, and it is estimated that about $25 \%$ of all cancer deaths show signs of aberrant Hh pathway activation [67].

Overproduction of Hh ligands (ligand dependent) [70,71] and/or genetic mutations of Hh pathway molecular components, such as loss-of-function mutations in negative pathway regulators (Ptch, SuFu, Hhip1) and gain-of-function mutations in Smo [39,66, 70, 71 ], can be the cause of Hh signaling hyperactivation in the pathogenesis of tumors. Gli1 and Gli2 gene amplification, Gli1 chromosomal translocation, or Gli2 protein stabilization also can determine ligand-independent hyperactivation of the Hh pathway [68] (๑ Table 1).

Genetic mouse models suggest that Hh signaling may contribute to the initiation of an aberrant progenitor population, which is then maintained in cancer as a tumor "stem cell" compartment, provides their self-renewal, and promotes the proliferation of tumor cells and tumor growth $[71,72]$ ( Fig. 4). In addition, it has been shown that Hh signaling plays an important role in epithelial-mesenchymal transition (EMT) and leads to an increase in cell motility with further cell invasion and metastasis [34]. Moreover it stimulates the differentiation of endothelial progenitor cells in tumors and induces the expression of angiopoietins I and II and vascular endothelial growth factors from mesenchymal cells. These findings highlight the significance of tumor-associ- 
Table 1 Altered Hedgehog components in different types of tumors.

\begin{tabular}{|c|c|c|c|}
\hline \multirow[t]{2}{*}{ Cancer type } & \multicolumn{3}{|c|}{ Altered Hh pathway components } \\
\hline & $\begin{array}{l}\text { Over- } \\
\text { expression }\end{array}$ & $\begin{array}{l}\text { Activating } \\
\text { mutations }\end{array}$ & $\begin{array}{l}\text { Inactivating } \\
\text { mutation }\end{array}$ \\
\hline Gorlin's syndrome & - & Smo & $\begin{array}{l}\text { Ptch1, SuFu, } \\
\text { p53 }\end{array}$ \\
\hline Medulloblastoma & - & Smo & Ptch1, SuFu \\
\hline $\begin{array}{l}\text { Esophageal squamous } \\
\text { cell carcinoma }\end{array}$ & $\mathrm{Hh}$ & - & Hhip1 \\
\hline Gastric cancer & $\mathrm{Hh}$ & - & Hhip1 \\
\hline Pancreatic cancer & $\mathrm{Hh}$ & - & Hhip1 \\
\hline Hepatocellular cancer & Shh, Gli & Smo & Hhip(?) \\
\hline Small-cell lung cancer & Shh & - & Hhip1 \\
\hline Prostate cancer & Shh & - & - \\
\hline Breast cancer & $\mathrm{Hh}, \mathrm{Gli}$ & Smo & Ptch1 \\
\hline
\end{tabular}

ated fibroblasts in combination with active Hh signaling in the formation of blood vessels, the enhancement of vessel permeability, and further tumor progression $[68,73]$.

Cyclopamine has been shown to have antitumor activity in several models of pancreatic, medulloblastoma, breast, prostate, small-cell lung, and digestive tract cancers $[65,69,70,74]$. The antitumor activity of cyclopamine is determined by increased apoptosis and cell differentiation, decreased cell proliferation and viability, and inhibition of cell migration, invasion, and EMT [39] (० Fig. 4).

\section{Hedgehog Signaling in Specific Types of Cancer and the Beneficial Effects of Cyclopamine \\ $\nabla$}

\section{Skin cancers}

The role of Hh signaling in cancer was first identified in individuals with Gorlin's syndrome, also known as basal cell nevus syndrome. Gorlin's syndrome is characterized by the presence of multiple basal cell carcinomas of the skin, abnormalities in facial and skeletal development, and a predisposition to medulloblas- tomas and rhabdomyosarcoma [75-78]. These are the most commonly diagnosed human cancers, and approximately 750000 basal cell carcinomas are treated each year in the United States alone [79].

The pathogenesis of basal cell carcinomas is characterized by mutations in Ptch1 (67\%), Smo (10\%), and SuFu (5\%) genes [67,76, 79-81].

Topical administration of cyclopamine inhibits the growth of malignant cells driven by $\mathrm{Hh}$ activation, shows effectiveness in the induction of differentiation and apoptosis in basal cell carcinomas, by reducing the size of lesions, and leads to the regression of sporadic basal cell carcinomas [76,79,81]. Similarly, oral cyclopamine treatment of Ptch1 C/K mice prevented basal cell carcinoma development after UV irradiation [82].

\section{Brain cancers}

Medulloblastoma, a tumor of cerebellar granule neuron progenitor cells, is a childhood cancer with an invariably poor prognosis [80]. During normal development, Shh is a mitogen for cerebellar granule neuron progenitors, and constitutive activation of this pathway in these cells due to inactivating mutations of Ptch1 and SuFu or activating mutations of Smo seems to give rise to medulloblastoma [80]. Similarly, in sporadic medulloblastomas loss or mutation of either Ptch1 or SuFu occurred in $10-20 \%$ and $41 \%$, respectively, of cases [76].

The use of cyclopamine was shown to decrease medulloblastoma cell growth in vitro and in vivo. Cyclopamine treatment on human medulloblastoma cell lines resulted in inhibition of cell division and loss of cell viability. When cyclopamine is administered on murine medulloblastoma cells, it inhibits their proliferation, downregulates expression of a neural stem cell marker, and stimulates expression of differentiation-associated genes [66]. In vitro, cyclopamine also drives medulloblastoma cells from a stem cell phenotype into a more differentiated state [83]. Rubin et al. suggested that $\mathrm{Hh}$ inhibition might have a more general effect on medulloblastoma cells than anticipated and that Hh antagonists might have the capacity to block the growth of all medulloblastomas, presumably because $\mathrm{Hh}$ has a mitogenic effect on these cells even when the pathway is not hyperactivated through

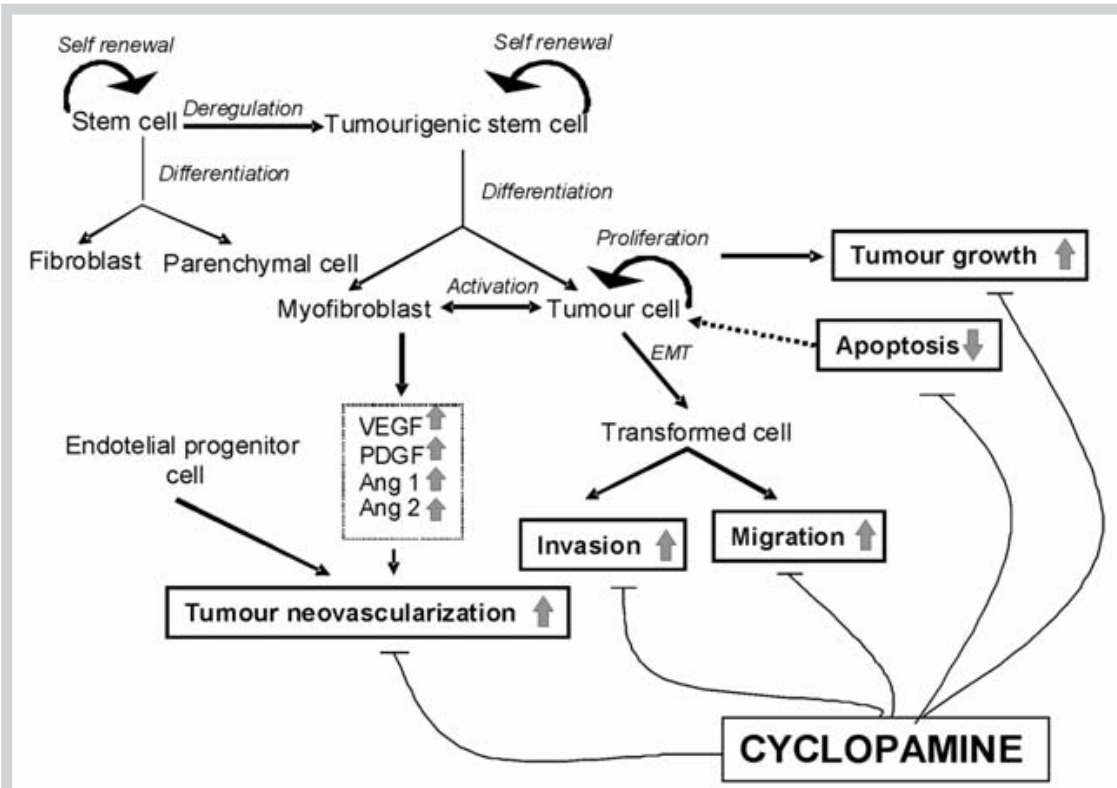

Fig. 4 Involvement of the Hedgehog pathway in tumorigenesis and the effects of cyclopamine. The pathways, which are stimulated by Hh signaling, are indicated in bold. Under physiological conditions, the Hh system provides the self-renewal of stem cells and participates in the maintenance of tissue structural homeostasis. In the case of hyperactivation, the Hh system converts stem cells into tumorigenic stem cells; maintains them in tumors; participates in the activating interactions between myofibroblasts and tumor cells; stimulates endothelial progenitor cells and the release of angiogenic factors from mesenchymal cells; inhibits apoptosis in tumor cells and leads to their proliferation; and stimulates EMT of tumor cells. As a result, hyperactivation of the Hh pathway leads to tumor neovascularization, growth, invasion, and metastasis. The antitumor activity of the Hh pathway antagonist cyclopamine is determined by an increase in apoptosis and cell differentiation; a decrease in tumor neovascularization, cell proliferation, and viability; and inhibition of EMT, cell migration and invasion. 
mutation [80]. Systemic administration of cyclopamine in a mouse model of medulloblastoma reduced tumor size and tumor cell number while increasing apoptosis. Systemic treatment in vivo thus appears to have beneficial effects $[66,82]$. Finally, as a small molecule, cyclopamine can cross the blood-brain barrier and be a valuable therapeutic remedy in the treatment of medulloblastoma [72,83].

Another type of brain cancer is glioblastoma multiforme, which is incurable and exhibits various degrees of astrocytic differentiation. It has recently been proposed that glioblastoma multiforme derives from neural stem or progenitor cells and that the survival of stem-like side population cells in glioblastoma is dependent on ongoing Hh pathway activity [84]. Hh pathway blockade by cyclopamine reduced growth and viability in glioma lines. Most significantly, cyclopamine therapy dramatically reduced the side and Aldefluor-positive populations present in glioblastoma multiforme cells, resulting in cultures no longer able to form colonies in vitro or xenografts in vivo [36].

\section{Gastrointestinal cancers}

Cancers in the gastrointestinal system account for a large proportion of malignancies and cancer-related deaths. Being vital and essential to the normal patterning of the gastrointestinal tract, it has been shown that the Hh pathway also plays a critical role in both the formation and the maintenance of gastrointestinal tract malignancies, including oral, esophageal, gastric, and intestinal cancers; pancreatic adenocarcinomas; and liver carcinoma and cholangiocarcinoma [39].

Nishimaki et al. showed a hyperactivation of the Hh system in oral squamous cell carcinoma. They also found that cyclopamine treatment induced a decrease in the number of cells and an increase in caspase-3 activity, indicating cell death [85].

The important determinants of esophageal squamous cell carcinoma and of gastric and pancreatic cancer development are the upregulation of Shh and the downregulation of Hhip1 $[68,75$, 76,86-88]. It has been revealed that hyperactivation of Shh signaling in these cancers is associated with the EMT, migration, and invasion of cancer cells and the stimulation of lymphatic metastasis, indicating the high malignant potential and poor prognosis of these cancers $[34,68,86]$. Moreover, Shh was shown to be involved in the tumor-associated angiogenesis in pancreatic cancers in a paracrine manner [87]. In addition, it is possible that the signaling pathways canonical WNT, BIRC3, TGM2, PLAU, and BMP2, which have been found to be mechanistically involved in pancreatic tumorigenesis, also might be activated as a downstream target of an active Hh pathway [89].

Experiments conducted on esophageal squamous cell carcinoma and on gastric and pancreatic cancer cells have shown that cyclopamine inhibits EMT, cell motility, and metastasis and reduces the malignant growth of cancer cells in vitro and in vivo $[34,68$, $70,81,86]$. It has been shown that Hh inhibition with cyclopamine enhances apoptosis in pancreatic cancer cells; inhibits their proliferation, invasion, and migration; and modulates the tumor microenvironment in pancreas [89]. Systemic administration of cyclopamine leads to the inhibition of pancreatic cancer growth and a marked reduction in tumor size as well as increases the cytotoxic effects of radiotherapy and chemotherapeutic agents [39,80,87-90].

The downregulation of Hhip 1 is also observed in colorectal cancers, in the pathogenesis of which the Hh system shows another behavior [86]. It has been suggested that Shh provides the proliferative stimulus in the colon, whereas Indian Hh promotes epi- thelial differentiation by inhibiting proliferation. With this in mind, it is important to understand the colonic distribution of Sonic and Indian $\mathrm{Hh}$ and their local biological properties. There is evidence that cross-talk within the Hh signaling pathway may prevent effective blockade of this pathway in some cancers [39]. Hepatocellular carcinoma is one of the most frequent human cancers worldwide and has a very poor prognosis, despite advances in early diagnosis and therapy. Recently, the aberrant activation of Hh signaling in hepatocellular carcinoma was reported [75]. It has been shown that the activating mutations of Smo or induced expression of Shh was the major trigger for Hh signal activation, though Gli2 overexpression has also been described recently. The implication of a negative regulator of Hh signaling in hepatocellular carcinoma pathogenesis was not fully investigated. Hh signaling plays a major role in multiple aspects of embryonic development, including that of the liver, and it is possible that the remaining $\mathrm{Hh}$ signal-responsive progenitor cells function as cancer stem cells in the liver, leading to the genesis of hepatocellular carcinoma. On the other hand, taking into account that $\mathrm{Hh}$ signaling regulates angiogenesis, as well as the role of Hhip downregulation during tube formation, the disruption of the Hhip gene may also play a role in the pathogenesis of vascular-rich hepatocellular carcinoma.

Treatment with cyclopamine reduces cell viability in hepatoma cell lines. Moreover, it has been shown that sensitivity to cyclopamine was higher in Hhip-null cell lines than in Hhip-expressing cell lines. As cyclopamine antagonizes Smo, but not Hhip, these results were not anticipated by the authors [77]. On the other hand, taking into account that in general the effect of a pharmacological agent depends on expression of pathological processes, it could be predicted that in Hhip-expressing cell lines, where Hhip in some manner depresses tumorigenic potential, the effect of cyclopamine in these cells can be smaller than that in Hhip-null cell lines. Cholangiocarcinoma is the second most common primary malignant tumor in the liver; its global incidence ranges from $5 \%$ to $25 \%$ among liver tumors and has been reported to be increasing steadily. It has a poor prognosis due to a low radical resection rate secondary to delayed diagnosis and complicated anatomy, as well as being resistant to conventional chemotherapy and radiotherapy. Recently completed studies suggest that the Hh pathway is important for cholangiocarcinoma cell proliferation and that its inhibition with cyclopamine decreases cell proliferation and arrests the cell cycle at the G1 phase [91].

\section{Lung cancer}

Small-cell lung cancer was the first identified Hh-overexpressing tumor. It is an aggressive, highly lethal malignancy with primitive neuroendocrine features [92]. It was discovered that about 25\% of human small-cell lung cancer samples have relatively high expression of both Shh and Gli1 $[75,80]$. On the other hand, downregulation of Hhip1 is also implicated in lung cancer [86]. Hh ligand communication to Ptch1-positive immune cells, including $\mathrm{CD} 4^{+} \mathrm{T}$ lymphocytes and macrophages, also can play a role in the pathogenesis of small-cell lung cancer [39]. Small-cell lung cancer cell lines appear to have developed a level of reliance on $\mathrm{Hh}$ signaling, whether autocrine or paracrine [66].

Cyclopamine treatment of small-cell lung cancer cell lines expressing both Shh and Gli1 inhibited their proliferation, downregulated stem cell markers, and increased apoptosis [92]. Subcutaneous injection of cyclopamine into animals carrying xenografts of small-cell lung cancer cell lines decreased tumor growth [66, 80]. 


\section{Prostate cancer}

Prostate cancer is a leading cause of male cancer-related deaths, and in the U.S. it is exceeded only by lung cancer.

The Hh pathway has recently been shown to be implicated in prostate cancer development and metastasis [38,93]. The overexpression of Hh ligands has been revealed to cause pathway activation in prostate carcinoma $[76,77,80]$. It was shown that exogenous expression of the Hh-dependent transcription factor Gli1 in low-metastatic rodent prostate carcinoma cells caused enhanced migration in vitro and development of visceral metastases in vivo [94].

Administration of cyclopamine causes downregulation of proliferation and initiation of apoptosis and blocks EMT with consequent reduction in tumor size and inhibition of metastasis. Cyclopamine in a lethal, metastatic rodent model of prostate cancer completely abrogated systemic metastases and dramatically improved survival $[38,82,93,94]$. The xenograft tumors derived from PC3 or 22RV1 cells grew more slowly and even regressed upon cyclopamine treatment. Remarkably, animals treated with the highest dose of cyclopamine, which caused complete prostate tumor regression, remained in remission even 70-148 days posttreatment [66].

\section{Breast cancer}

Despite advances in detection and therapies, breast cancer is still the leading cause of cancer death in women worldwide $[95,96]$. Activation of the Hh signaling pathway has been shown to result in the generation of mammary carcinomas. An aberrant activation of the Hh pathway in different types of breast cancers can be determined by overexpression of Hh ligands and Smo or by the loss of Ptch1 [37,76,97,98].

It has been proposed that hyperactivation of Hh signaling contributes to breast cancer through deregulation of the mammary stem cell compartment and alteration of epithelial-stromal interaction of normal and transformed epithelial cells [37,99]. Liu et al. identified high-level expression of Hh pathway components in benign and malignant breast epithelial progenitors.

Treatment with cyclopamine inhibits growth and proliferation of a subset of breast cell lines, reduces their viability, and induces apoptosis $[76,97]$. It has been shown that cyclopamine inhibits the self-renewal of mammary stem cells and the proliferation of progenitor cells, but presumably cyclopamine may act here independently of Smo [37].

\section{Implication of the Hh System in Psoriasis and the Effectiveness of Cyclopamine \\ $\nabla$}

Psoriasis is a common chronic inflammatory, disfiguring skin disease characterized by complex alterations in epidermal growth and differentiation and by multiple immunological and vascular abnormalities $[78,100]$. Activation of T lymphocytes plays a central role in the pathogenesis of psoriasis. Activated T lymphocytes secrete cytokines, which lead to proliferation and decreased maturation of keratinocytes [100]. It also emphasizes the role of transcription factors, which are involved in cell proliferation/differentiation, immune/inflammatory responses, and lipid metabolism, in the pathogenesis of psoriasis [101].

It has been suggested that the Hh pathway is activated in lesional psoriatic skin. An activation of this pathway in keratinocytes induces hyperproliferation and resistance to exhaustion of replicative growth capacity. Additionally, the Hh pathway has also been implicated in modulation of the immune function of $\mathrm{T}$ cells in a proinflammatory manner, suggesting that the involvement of this pathway in psoriasis pathogenesis might be plausible. Here the possible influence of the Hh pathway on transcription factors also can have a role in the pathogenesis of psoriasis. It has been shown that the inhibition of neurofibromin (which mediates inhibitory signals against the Hh signaling pathway) expression can lead to activation of the Hh system in lesional keratinocytes in psoriasis [100].

Pharmacological inhibition of the Hh pathway using cyclopamine leads to rapid and expressed resolution of the disease $[78,100]$. Cyclopamine-treated lesions developed a sharply demarcated circular area of vasoconstriction, which is consistent with capillary morphogenesis induced by Hh signaling [101]. Yet treatment of the psoriatic lesional skin with cyclopamine caused rapid disappearance of the $\mathrm{T}$ lymphocytes and other inflammatory cells that infiltrate such skin $[35,102]$. Moreover, topical administration of cyclopamine appears to be more effective than the potent topical steroid clobetasol-17 propionate, a typical first-line therapy.

However, Gudjonsson et al. could not confirm previously published studies on the activation of the Hh pathway in lesional psoriasis; on the contrary, their results indicate that this pathway may be modestly suppressed. They conclude that the effect of cyclopamine, if truly effective in psoriasis, is likely to be mediated through a mechanism other than blockade of Hh signaling [78].

\section{Potential Hazards and Future Perspectives} $\nabla$

Though cyclopamine, in the first enthusiasm about its anticancer effects, was promised a golden future, it is now obvious, in the light of the aforementioned widespread interactions with the normal tissues of adult body, that its action has a Janus face. Given that Hh signaling is required in the stem cell niches of various tissues such as the gonads, gastrointestinal tract, and bone marrow, a major pitfall of this otherwise promising cancer therapy is its potential for "on-target" toxicity on somatic stem cells occurring as a result of inhibition of the intended target (i.e., Hh) in non-cancerous cells [38]. Even when applied topically, as during treatment of psoriasis, cyclopamine could have adverse effects on epidermal/hair follicle stem cells [35]. Furthermore, during chronic systemic application, considerable changes in fat metabolism as well as in cardiovascular and immune system functioning may occur. Nonetheless, the balance between beneficial and adverse effects may vary depending on the type of delivery, the dose, and the duration of treatment as well as on the presence of other drugs (e.g., chemotherapeutic agents [100]). These promising aspects have prompted the search for diverse smallmolecule inhibitors of Hh signaling based on cyclopamine or other leads [103], and a phase I clinical trial has already been started with notable results [104]. In the end, sophisticated and correct use of the principally teratogenic and hazardous constituent of Veratrum californicum, cyclopamine, may make it applicable as a beneficial therapeutic remedy against cancers and other pathologies.

\section{Acknowledgements}

$\nabla$

The authors thank Dr. Athanassios Giannis (University of Leipzig) for providing a high-quality image of $\odot$ Fig. 1. 


\section{References}

1 Binns W, James LF, Shupe JL, Everett G. A congenital cyclopean-type malformation in lambs induced by maternal ingestion of a range plant, Veratrum californicum. Am J Vet Res 1963; 24: 1164-1175

2 Keeler RF. Teratogenic compounds of Veratrum californicum (Durand) X. Cyclopia in rabbits produced by cyclopamine. Teratology 1970; 3: $175-180$

3 Keeler RF. Teratogenic effects of cyclopamine and jervine in rats, mice and hamsters. Proc Soc Exp Biol Med 1975; 149: 302-306

4 Bryden MM, Perry C, Keeler RF. Effects of alkaloids of Veratrum californicum on chick embryos. Teratology 1973; 8: 19-28

5 Cohen Jr MM, Shiota K. Teratogenesis of holoprosencephaly. Am J Med Genet 2002; 109: 1-15

6 Siebert JR, Cohen Jr MM, Sulik KK, Shaw C-M, Lemire RJ. Holoprosencephaly. An overview and atlas of cases. New York: Wiley-Liss; 1990

7 Keeler RF. Livestock models of human birth defects, reviewed in relation to poisonous plants. J Animal Sci 1988; 66: 2414-2427

8 Keeler RF, Binns W. Teratogenic compounds of Veratrum californicum (Durand). V. Comparison of cyclopean effects of steroidal alkaloids from the plant and structurally related compounds from other sources. Teratology 1968; 1: 5-10

9 Keeler RF. Cyclopamine and related steroidal alkaloid teratogens: their occurrence, structural relationship, and biological effects. Lipids 1978; 13: $708-715$

10 Cong Y, Guo L, Yang JY, Li L, Zhou YB, Chen J, Wang JH. Steroidal alkaloids from Veratrum japonicum with genotoxicity on brain cell DNA of the cerebellum and cerebral cortex in mice. Planta Med 2007; 73: 15881591

11 Cong Y, Zhou YB, Chen J, Zeng YM, Wang JH. Alkaloid profiling of crude and processed Veratrum nigrum L. through simultaneous determination of ten steroidal alkaloids by HPLC-ELSD. J Pharm Biomed Anal 2008; 48: 573-578

12 Schep LJ, Schmierer DM, Fountain JS. Veratrum poisoning. Toxicol Rev 2006; 25: 73-78

13 Ma R, Ritala A, Oksman-Caldentey KM, Rischer H. Development of in vitro techniques for the important medicinal plant Veratrum californicum. Planta Med 2006; 72: 1142-1148

14 Roessler E, Belloni E, Gaudenz K, Jay P, Berta P, Scherer SW, Tsui LC, Muenke M. Mutations in the human Sonic Hedgehog gene cause holoprosencephaly. Nat Genet 1996; 14: 357-360

15 Chiang C, Litingung Y, Lee E, Young KE, Corden JE, Westphal H, Beachy PA. Cyclopia and defective axial patterning in mice lacking sonic hedgehog gene function. Nature 1996; 383: 407-413

16 Cooper MK, Porter JA, Young KE, Beachy PA. Teratogen-mediated inhibition of target tissue response to Shh signalling. Science 1998; 280: 1603-1607

17 Bijlsma MF, Spek CA, Peppelenbosch MP. Hedgehog: an unusual signal transducer. Bioessays 2004; 26: 387-394

18 Hooper JF, Scott MP. Communicating with hedgehogs. Nat Rev Mol Cell Biol 2005; 6: 306-317

19 Ingham PW, Placzek $M$. Orchestrating ontogenesis: variations on a theme by sonic hedgehog. Nat Rev Genet 2006; 7: 841-850

20 Eaton S. Multiple roles for lipids in the Hedgehog signalling pathway. Nat Rev Mol Cell Biol 2008; 9: 437-445

21 Variosalo M, Taipale J. Hedgehog: functions and mechanisms. Genes Dev 2008; 22: 2454-2472

22 Mann RK, Beachy PA. Novel lipid modifications of secreted protein signals. Ann Rev Biochem 2004; 73: 891-923

23 Miura GI, Treisman JE. Lipid modification of secreted signaling proteins. Cell Cycle 2006; 5: 1184-1188

24 Torroja C, Gorfinkel N, Guerrero I. Mechanisms of hedgehog gradient formation and interpretation. J Neurobiol 2005; 64: 334-356

25 Dessaud E, Yang LL, Hill K, Cox B, Ulloa F, Ribeiro A, Mynett A, Novitch BG, Briscoe J. Interpretation of the sonic hedgehog morphogen gradient by a temporal adaptation mechanism. Nature 2007; 450: 717-721

26 Panakova D, Sprong H, Marois E, Thiele C, Eaton S. Lipoprotein particles are required for Hedgehog and Wingless signaling. Nature 2005; 435 : $58-65$

27 Bijlsma MF, Spek CA, Zivkovic D, van de Water S, Rezaee F, Peppelenbosch MP. Repression of smoothened by patched-dependent (pro)vitamin D3 secretion. PLoS Biol 2006; 18: 1397-1410

28 Taipale J, Cooper MK, Maiti T, Beachy PA. Patched acts catalytically to suppress the activity of Smoothened. Nature 2002; 418: 892-897

29 Dennler S, André J, Alexaki I, Li A, Magnaldo T, ten Dijke P, Wang XJ, Verrecchia $F$, Mauviel A. Induction of sonic hedgehog mediators by trans- forming growth factor-beta: Smad3-dependent activation of Gli2 and Gli1 expression in vitro and in vivo. Cancer Res 2007; 67: 6981-6986

30 Pan Y, Wong B. A novel protein-processing domain in Gli2 and Gli3 differentially blocks complete protein degradation by the proteasome. J Biol Chem 2007; 282: 10846-10852

31 Fernández-Zapico ME. Primers on molecular pathways. Gli: more than just hedgehog? Pancreatology 2008; 8: 227-229

32 Chen JK, Taipale J, Cooper MK, Beachy PA. Inhibition of hedgehog signaling by direct binding of cyclopamine to Smoothened. Genes Dev 2002; 16: $2743-2748$

33 Mistretta CM, Liu HX, Gaffield W, MacCallum DK. Cyclopamine and jervine in embryonic rat tongue cultures demonstrate a role for Shh signaling in taste papilla development and patterning: fungiform papillae double in number and form innovel locations in dorsal lingual epithelium. Dev Biol 2003; 254: 1-18

34 Yoo YA, Kang MH, Kim JS, Oh SC. Sonic hedgehog signaling promotes motility and invasiveness of gastric cancer cells through TGF-b-mediated activation of the ALK5-Smad 3 pathway. Carcinogenesis 2008; 29: $480-490$

35 Taş S, Avcıb O. Rapid clearance of psoriatic skin lesions induced by topical cyclopamine. Dermatology 2004; 209: 126-131

36 Bar EE, Chaudry A, Lin A, Fan X, Schreck K, Matsui W, Piccirillo S, Vescovi AL, DiMeco F, Olivi A, Eberhart CG. Cyclopamine-mediated hedgehog pathway inhibition depletes stem-like cancer cells in glioblastoma. Stem Cells 2007; 25: 2524-2533

37 Liu S, Dontu G, Mantle ID, Patel S, Ahn NS, Jackson KW, Suri P, Wicha MS. Hedgehog signaling and Bmi-1 regulate self-renewal of normal and malignant human mammary stem cells. Cancer Res 2006; 66: 60636071

38 Kumar SK, Roy I, Anchoori RK, Fazli S, Maitra A, Beachy PA, Khan SR. Targeted inhibition of hedgehog signaling by cyclopamine prodrugs for advanced prostate cancer. Bioorg Med Chem 2008; 16: 2764-2768

39 Lees C, Howie S, Sartor BR, Satsangi J. The hedgehog signalling pathway in the gastrointestinal tract: implications for development, homeostasis, and disease. Gastroenterology 2005; 129: 1696-1710

40 Parga JA, Rodriguez-Pallares J, Blanco V, Guerra MJ, Labandeira-Garcia $J L$. Different effects of anti-sonic hedgehog antibodies and the hedgehog pathway inhibitor cyclopamine on generation of dopaminergic neurons from neurospheres of mesencephalic precursors. Dev Dyn 2008; 237: 909-917

41 Hashimoto M, Ishii K, Nakamura Y, Watabe K, Kohsaka S, Akazawa C. Neuroprotective effect of sonic hedgehog up-regulated in Schwann cells following sciatic nerve injury. J Neurochem 2008; 107: 918-927

42 Charytoniuk D, Porcel B, Rodríguez Gomez J, Faure H, Ruat M, Traiffort E. Sonic Hh signalling in the developing and adult brain. J Physiol Paris 2002; 96: 9-16

43 Van den Brink GR, Bleuming SA, Hardwick JCH, Schepman BL, Offerhaus GJ, Keller JJ, Nielsen C, Gaffield W, van Deventer SJ, Roberts DJ, Peppelenbosch MP. Indian hedgehog is an antagonist of Wnt signalling in colonic epithelial cell differentiation. Nature Genet 2004; 36: 277-282

44 Omenetti A, Diehl AM. The adventures of sonic hedgehog in development and repair. II. Sonic hedgehog and liver development, inflammation, and cancer. Am J Physiol Gastrointest Liver Physiol 2008; 294: G595-598

45 Szczepnya A, Hogartha CA, Younga J, Lovelanda KL. Identification of Hedgehog signalling outcomes in mouse testis development using a hanging-drop culture system. Biol Reprod 2009; 80: 258-263

46 Varas A, Carmen HL, Jaris V, Silvia M, Martínez VG, Hidalgo L, GutiérrezFrías C, Zapata AG, Sacedón R, Vicente A. Survival and function of human thymic dendritic cells are dependent on autocrine Hedgehog signaling. J Leukoc Biol 2008; 83: 1476-1483

47 Lavine KJ, Kovacs A, Ornitz DM. Hedgehog signalling is critical for maintenance of the adult coronary vasculature in mice. J Clin Invest 2008; 7: 2404-2414

48 Bijlsma MF, Spek AC, Peppelenbosch MP. Hedgehog turns lipoproteins into janus-faced particles. Cardiovasc Med 2006; 16: 217-220

49 Bijlsma MF, Peppelenbosch MP, Spek AC. Hedgehog morphogen in cardiovascular disease. Circulation 2006; 114: 1985-1991

50 Bijlsma MF, Leenders PJ, Janssen BJ, Peppelenbosch MP, Ten Cate H, Spek $C A$. Endogenous hedgehog expression contributes to myocardial ischemia-reperfusion-induced injury. Exp Biol Med (Maywood) 2008; 233 : 989-996

51 Ohba S, Kawaguchi H, Kugimiya F, Ogasawara T, Kawamura N, Saito T, Ikeda T, Fujii K, Miyajima T, Kuramochi A, Miyashita T, Oda H, Nakamura $K$, Takato T, Chung UI. Patched1 haploinsufficiency increases adult bone 
mass and modulates Gli3 repressor activity. Dev Cell 2008; 14: 689699

52 Gesta S, Tseng Y, Kahn C. Developmental origin of fat: tracking obesity to its source. Cell 2007; 135: 366

53 Cousin W, Fontaine C, Dani C, Peraldi P. Hedgehog and adipogenesis: Fat and fiction. Biochimie 2007; 89: 1447-1453

54 Suh J, Gao X, McKay J, McKay R, Salo Z, Graff J. Hedgehog signaling plays a conserved role in inhibiting fat formation. Cell Metab 2006; 3: 25-34

55 Fontaine C, Cousin W, Plaisant M, Dani C, Peraldi P. Hedgehog signaling alters adipocyte maturation of human mesenchymal stem cells. Stem Cells 2008; 26: 1037-1046

56 Cousin W, Dani C, Peraldi P. Inhibition of the anti-adipogenic hedgehog signaling pathway by cyclopamine does not trigger adipocyte differentiation. Biochem Biophys Res Commun 2006; 349: 799-803

57 Horst G, Sips H, Lowik C, Karperien M. Hedgehog stimulates only osteoplastic differentiation of undifferentiated Ks483 cells. Bone 2003; 33: 899-910

58 Martin PI, Lane J, Pouliot L, Gains M, Stejskal R, Smith Y, Galdes A, Green J. Increases in adipose and total body weight, but not in lean body mass, associated with subcutaneous administration of sonic hedgehog-Ig fusion protein to mice. Drug DevRes 2002; 57: 107-114

59 Goodrich L, Milenkovic M, Higgins K, Scott M. Altered neural cell fates and medulloblastoma in mouse patched mutants. Science 1997; 277 : 1109-1113

60 Gorlin $R$. Nevoid basal cell cacrinoma syndrome. Medicine (Baltimore) 1987; 66: 98-113

61 Buhman K, Wang L, Tang Y, Swietlicki E, Kennedy S, Xie Y, Liu Z, Burkly L Levin $M$, Rubin D, Davidson N. Inhibition of Hedgehog signaling protects adult mice from diet-induces weight gain. J Nutr 2004; 134 : 2979-2984

62 Wang LC, Nassir F, Liu ZY, Ling L, Kuo F, Crowell T, Olson D, Davidson NO, Burkly LC. Disruption of hedgehog signalling reveals a novel role in intestinal morphogenesis and intestinal-specific lipid metabolism in mice. Gastroenterology 2002; 122: 469-482

63 Beckers L, Heeneman S, Wang L, Burkly LC, Rouch MMJ, Davidson NO, Gijbels MJ, de Winther MP, Daemen MJ, Lutgens E. Disruption of hedgehog signalling in ApoE-/- mice reduces plasma lipid levels, but increases atherosclerosis due to enhanced lipid uptake by macrophages. J Pathol 2007: 212: 420-428

64 Li Z, Zhang H, Denhradt L, Liu L, Zhou H, Lan Z. Reduced white fat mass in adult mice bearing a truncated Patched 1. Int J Biol Sci 2008; 4: 29-36

65 Watkins DN, Peacock CD. Hedgehog signalling in foregut malignancy. Biochem Pharmacol 2004; 68: 1055-1060

66 Datta S, Datta MW. Sonic Hedgehog signaling in advanced prostate cancer. Cell Mol Life Sci 2006; 63: 435-448

67 Lauth $M$, Toftgård $R$. Non-canonical activation of GLI transcription factors. Cell Cycle 2007; 6: 2458-2463

68 Bailey JM, Singh PK, Hollingsworth MA. Cancer metastasis facilitated by developmental pathways: sonic hedgehog, notch, and bone morphogenic proteins. J Cell Biochem 2007; 102: 829-839

69 Tremblay MR, Nevalainen M, Nair SJ, Porter JR, Castro AC, Behnke ML, Yu LC, Hagel M, White K, Faia K, Grenier L, Campbell MJ, Cushing J, Woodward CN, Hoyt J, Foley MA, Read MA, Sydor JR, Tong JK, Palombella VJ, McGovern K, Adams J. Semisynthetic cyclopamine analogues as potent and orally bioavailable hedgehog pathway antagonists. J Med Chem 2008; 51: 6646-6649

70 Yanai K, Nagai S, Wada J, Yamanaka N, Nakamura M, Torata N, Noshiro $H$, Tsuneyoshi $M$, Tanaka $M$, Katano $M$. Hedgehog signaling pathway is a possible therapeutic target for gastric cancer. J Surg Oncol 2007; 95: 55-62

71 Abe Y, Oda-Sato E, Tobiume K, Kawauchi K, Taya Y, Okamoto K, Oren M, Tanaka $N$. Hedgehog signaling overrides p53-mediated tumor suppression by activating Mdm2. Proc Natl Acad Sci USA 2008; 105 4838-4843

72 Peacock CD, Wang Q, Gesell GS, Corcoran-Schwartz IM, Jones E, Kim J, Devereux WL, Rhodes JT, Huff CA, Beachy PA, Watkins DN, Matsui W. Hedgehog signaling maintains a tumor stem cell compartment in multiple myeloma. Proc Natl Acad Sci USA 2007; 104: 4048-4053

73 Geng L, Cuneo KC, Cooper MK, Wang H, Sekhar K, Fu A, Hallahan DE. Hedgehog signaling in the murine melanoma microenvironment. Angiogenesis 2007; 10: 259-267

74 James LF, Panter KE, Gaffield W, Molyneux RJ. Biomedical applications of poisonous plant research. J Agric Food Chem 2004; 52: 3211-3230
75 He J, Sheng T, Stelter AA, Li C, Zhang X, Sinha M, Luxon BA, Xie J. Suppressing Wnt signaling by the Hedgehog pathway through sFRP-1. J Biol Chem 2006; 281: 35598-35602

76 Hatsell S, Frost AR. Hedgehog signaling in mammary gland development and breast cancer. J Mammary Gland Biol Neoplasia 2007; 12: 163-173

77 Tada M, Kanai F, Tanaka Y, Tateishi K, Ohta M, Asaoka Y, Seto M, Muroyama R, Fukai K, Imazeki F, Kawabe T, Yokosuka O, Omata M. Downregulation of hedgehog-interacting protein through genetic and epigenetic alterations in human hepatocellular carcinoma. Clin Cancer Res 2008; 14: 3768-3776

78 Gudjonsson JE, Aphale A, Grachtchouk M, Ding J, Nair RP, Wang T, Voorhees JJ, Dlugosz AA, Elder JT. Lack of evidence for activation of the hedgehog pathway in psoriasis. J Invest Dermatol 2009; 129: 635-640

79 Epstein EH. Basal cell carcinomas: attack of the hedgehog. Nature Rev 2008; 8: 743-754

80 Rubin LL, de Sauvage FJ. Targeting the Hedgehog pathway in cancer. Nature Rev 2006; 5: 1026-1033

81 Lupi 0 . Correlations between the Sonic Hedgehog pathway and basal cell carcinoma. Int J Dermatol 2007; 46: 1113-1117

82 Stecca B, Mas C, Altaba AR. Interference with HH-GLI signaling inhibits prostate cancer. Trends Mol Med 2005; 11: 199-203

83 Clark PA, Treisman DM, Ebben J, Kuo JS. Developmental signaling pathways in brain tumor-derived stem-like cells. Dev Dyn 2007; 236 3297-3308

84 Ehtesham M, Sarangi A, Valadez JG, Chanthaphaychith S, Becher MW, Abel TW, Thompson RC, Cooper MK. Ligand-dependent activation of the hedgehog pathway in glioma progenitor cells. Oncogene 2007; 26 : 5752-5761

85 Nishimaki H, Kasai K, Kozaki K, Takeo T, Ikeda H, Saga S, Nitta M, Itoh G. A role of activated Sonic hedgehog signaling for the cellular proliferation of oral squamous cell carcinoma cell line. Biochem Biophys Res Commun 2004; 314: 313-320

86 Katoh Y, Katoh M. Hedgehog signaling pathway and gastrointestinal stem cell signaling network. Int J Mol Med 2006; 18: 1019-1023

87 Yamazaki M, Nakamura K, Mizukami Y, Ii M, Sasajima J, Sugiyama $Y$, Nishikawa T, Nakano Y, Yanagawa N, Sato K, Maemoto A, Tanno S, Okumura T, Karasaki H, Kono T, Fujiya M, Ashida T, Chung DC, Kohgo Y. Sonic hedgehog derived from human pancreatic cancer cells augments angiogenic function of endothelial progenitor cells. Cancer Sci 2008; 99: $1131-1138$

88 Lee CJ, Dosch J, Simeone DM. Pancreatic cancer stem cells. J Clin Oncol 2008; 26: 2806-2812

89 Feldmann G, Habbe $N$, Dhara S, Bisht S, Alvarez H, Fendrich V, Beaty $R$ Mullendore M, Karikari C, Bardeesy N, Ouellette MM, Yu W, Maitra A. Hedgehog inhibition prolongs survival in a genetically engineered mouse model of pancreatic cancer. Gut 2008; 57: 1420-1430

90 Shafaee Z, Schmidt H, Du W, Posner M, Weichselbaum R. Cyclopamine increases the cytotoxic effects of paclitaxel and radiation but not cisplatin and gemcitabine in Hedgehog expressing pancreatic cancer cells. Cancer Chemother Pharmacol 2006; 58: 765-770

91 Jinawath A, Akiyama Y, Sripa B, Yuasa Y. Dual blockade of the Hedgehog and ERK1/2 pathways coordinately decreases proliferation and survival of cholangiocarcinoma cells. J Cancer Res Clin Oncol 2007; 133: 271 278

92 Watkins DN, Berman DM, Burkholder SG, Wang B. Hedgehog signalling within airway epithelial progenitors and in small-cell lung cancer. Nature 2003; 422: 313-317

93 Shaw G, Prowse DM. Inhibition of androgen-independent prostate cancer cell growth is enhanced by combination therapy targeting Hedgehog and ErbB signaling. Cancer Cell Int 2008; 18: 8-3

94 Fendrich V, Waldmann J, Esni F, Ramaswamy A, Mullendore M, Buchholz M, Maitra A, Feldmann G. Snail and Sonic Hedgehog activation in neuroendocrine tumors of the ileum. Endocr Relat Cancer 2007; 14: 865874

95 Iorio MV, Casalini P, Tagliabue E, Ménard S, Croce CM. MicroRNA profiling as a tool to understand prognosis, therapy response and resistance in breast cancer. Eur J Cancer 2008; 44: 2753-2759

96 Mehta RG, Naithani R, Huma L, Hawthorne M, Moriarty RM, McCormick $D L$, Steele VE, Kopelovich L. Efficacy of chemopreventive agents in mouse mammary gland organ culture (MMOC) model: a comprehensive review. Curr Med Chem 2008; 15: 2785-2825

97 Kubo M, Nakamura M, Tasaki A, Yamanaka N, Nakashima H, Nomura M, Kuroki S, Katano M. Hedgehog signaling pathway is a new therapeutic target for patients with breast cancer. Cancer Res 2004; 64: 6071-6074 
98 Zhang $X$, Harrington $N$, Moraes RC, Wu MF, Hilsenbeck SG, Lewis MT. Cyclopamine inhibition of human breast cancer cell growth independent of Smoothened (Smo). Breast Cancer Res Treat 2009; 115: 505-521

99 Kasper M, Jaks V, Fiaschi M, Toftgård R. Hedgehog signalling in breast cancer. Carcinogenesis 2009; 30: 903-911

100 Endo H, Momota Y, Oikawa A, Shinkai H. Psoriatic skin expresses the transcription factor Gli1: possible contribution of decreased neurofibromin expression. Br J Dermatol 2006; 154: 619-623
101 Kuenzli S, Sorg O, Saurat JH. Cyclopamine, Hedgehog and psoriasis. Dermatology 2004; 209: 81-83

102 McFerren MA. Useful plants of dermatology. VIII. The false hellebore (Veratrum californicum). J Am Acad Dermatol 2006; 54: 718-720

$103 \mathrm{Xie}$ J. Implications of hedgehog signaling antagonists for cancer therapy. Acta Biochim Biophys Sin (Shanghai) 2008; 40: 670-680

104 Zhang J, Garrossian M, Gardner D, Garrossian A, Chang YT, Kim YK, Chang CW. Synthesis and anticancer activity studies of cyclopamine derivatives. Bioorg Med Chem Lett 2008; 18: 1359-1363 